\title{
Carbon nanotubes synthesis using diffusion and premixed flame methods: a review
}

\author{
Garima Mittal ${ }^{1}$, Vivek Dhand ${ }^{1}$, Kyong Yop Rhee ${ }^{1, \diamond}$, Hyeon-Ju Kim² and Dong Ho Jung ${ }^{2}$ \\ ${ }^{1}$ Department of Mechanical Engineering, College of Engineering, Kyung Hee University, Yongin 446-701, Korea \\ ${ }^{2}$ Maritime and Ocean Engineering Research Institute, Korea Institute of Ocean Science and Technology, Daejeon 305-600, Korea
}

\section{Article Info}

Received 15 December 2014

Accepted 15 January 2015

*Corresponding Author

E-mail: rheeky@khu.ac.kr

Tel: +82-31-201-2565

\section{Open Access}

DOI: http://dx.doi.org/

10.5714/CL.2015.16.1.001

This is an Open Access article distributed under the terms of the Creative Commons Attribution Non-Commercial License (http://creativecommons.org/licenses/ by-nc/3.0/) which permits unrestricted non-commercial use, distribution, and reproduction in any medium, provided the original work is properly cited.

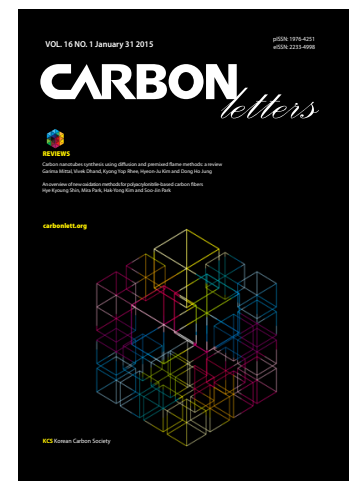

http://carbonlett.org

pISSN: 1976-4251

elSSN: 2233-4998

Copyright $\odot$ Korean Carbon Society

\begin{abstract}
In recent years, flame synthesis has absorbed a great deal of attention as a combustion method for the production of metal oxide nanoparticles, carbon nanotubes, and other related carbon nanostructures, over the existing conventional methods. Flame synthesis is an energyefficient, scalable, cost-effective, rapid and continuous process, where flame provides the necessary chemical species for the nucleation of carbon structures (feed stock or precursor) and the energy for the production of carbon nanostructures. The production yield can be optimized by altering various parameters such as fuel profile, equivalence ratio, catalyst chemistry and structure, burner configuration and residence time. In the present report, diffusion and premixed flame synthesis methods are reviewed to develop a better understanding of factors affecting the morphology, positioning, purity, uniformity and scalability for the development of carbon nanotubes along with their correlated carbonaceous derivative nanostructures.
\end{abstract}

Key words: flame synthesis, diffusion flame, premixed flame, carbon nano structures, nanotubes

\section{Introduction}

Carbon is a fundamental element found in a diverse range of natural structures, and can be obtained through versatile techniques. Carbonaceous structures are employed in a wide range of applications because of their outstanding mechanical, electrical, and thermal properties [1-4]. Over the last few decades, the development of novel carbonaceous structures, such as active carbon [5,6], carbon nanotubes (CNTs) or carbon nanofibers (CNFs) [7-10], carbon spheroids [11], carbon onions [12], fullerenes [13], and glassy carbon [14] have attracted much scientific interest. Among these structures, CNTs are the most relevant because their unique arrangement of carbon atoms produces remarkable properties, such as high aspect ratio, young's modulus, and conductivity [15-17]. All these properties depend on the production method [18]. The first CNTs were initially synthesized by the arc-discharge method by Ijima in 1991 [19]. Since that discovery, numerous other production methods have been used to synthesize CNTs, including chemical-vapor deposition (CVD) [20-22], laser ablation [23,24], and electrochemical synthesis [25]. However, these production methods are usually difficult to control, highly expensive, non-continuous (batch process), and not scalable for large-scale synthesis [26], and they require a high degree of energy. To accomplish the large-scale production needed for industrial applications, the flame synthesis method can be used, which is a cost-effective process with controlled energy, high growth rate, scalability, and continuity $[27,28]$.

Although this method is well established, it has not been extensively studied as a CNT production technique. Before the introduction of CNTs, carbon black was the most commercially available carbon material synthesized through flame synthesis. The earliest carbo- 
naceous tube-like structures produced through flame synthesis were observed by Singer in 1950 [29]. The essential components for the catalytic CNT synthesis are basically gaseous carbon and a heat source as well as catalysts. Typically, a gaseous mixture of hydrocarbons is supplied at a constant pressure and temperature throughout the reactor; a metal nanoparticle catalyst acts as an interface between the gaseous reactants and solid carbon precursors by lowering the energy constraints for CNT growth [30]. In this method, gaseous hydrocarbons serve as carbon precursors, while the flame provides the high temperature required for the synthesis. Carbon monoxide, methane, ethane, ethene, and acetylene are typically used as inexpensive gaseous carbon sources. The metal catalyst, which provides the reaction sites for carbon, can be introduced into the system in the form of a substrate or aerosol deposition [31-33]. The structural properties of the CNTs can thus be controlled by scaling the temperature, pressure, and heating rate, or by selecting a specific catalyst, solvent, and fuel profile [34]

In comparison to conventional methods, flame synthesis is a rapid process that can be completed in the order of tens of milliseconds [35]. The growth mechanism can vary depending on the carbon precursors, catalysts, and operation parameters. Three major steps are involved in the growth mechanism of the CNTs [36,37]: 1) catalytic deposition of the carbon precursor molecule on the surface of a metal catalyst; 2) diffusion of carbon atoms over the catalyst particle until supersaturation; 3 ) formation of hollow graphitic tubes. Nanocatalysts ensure better results, as the solubility of carbon precursors onto the catalysts increases with the surface area of the catalysts. A variety of carbon structures can be obtained by altering the operation parameters such as the equivalence ratio (which is the ratio of the oxidizer to the fuel used), flame configuration, etc. [38]. These carbon nanostructures can be used in a variety of applications such hydrogen storage, field-emission displays, nanoelectronics, hydrogen production, and lithium-ion batteries [24,39-46].

In the flame synthesis process, the type of synthesis is defined as either diffusion or premixed flame synthesis depending

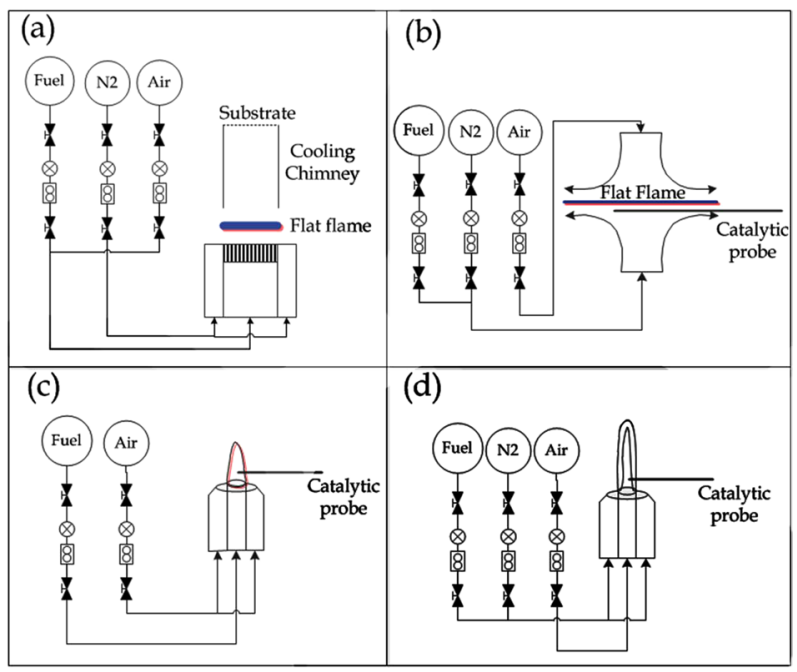

Fig. 1. Schematic representation of the flame synthesis: (a) premixed flame, (b) counter-flow diffusion flame, (c) co-flow diffusion flame, and (d) inverse diffusion flame. Reprinted with permission from [47]. on the entrainment of the oxidizer. In diffusion flame synthesis, the oxidizer and fuel combine separately by diffusion; the three possible orientations of the diffusion flames are co-flow diffusion, inverse diffusion, and counter diffusion. When the fuel is introduced through the inner tube and the oxidizer from the outer tube, the orientation is defined as co-flow diffusion; if the positions of the fuel and oxidizer are reversed, this is defined as inverse diffusion. In counter diffusion, the fuel and oxidizer are introduced through different tubes, but their flow directions are different. In premixed flames, as contrasted with diffusion flames, the fuel and oxidizer are mixed before combustion. Fig. 1 shows the schematic representation of the arrangement of these different flame methods [47].

In this review, different flame synthesis techniques are described for a simple and large-scale production of CNTs. Additionally, the effects of various parameters, including flame configuration, catalyst properties, hydrocarbon choice, height and radial effects, are also discussed that may provide relevant information for the optimization of large-scale synthesis.

\section{Diffusion Flame Synthesis}

The formation of tubular carbonaceous structures from flame synthesis was firstly reported by Singer and Grumer, long before the discovery of CNTs by Iijima [19]. However, no evidence of CNT formation was provided in the Singer and Grumer studies because of rudimentary microscopes. A few years later, Saito et al. [48] presented a report on the synthesis of elongated carbon fibers through the diffusion flame method with different hydrocarbons (methane, ethane, ethene, acetylene, propane, allene 1-butene, 1,3-butadiene, and benzene) in co-flowing normal atmospheric oxygen. Their main focus was on soot formation at different heights from the burner. Using scanning electron microscope (SEM) and electron spectroscopy for chemical analysis (ESCA), they observed that surface smoothness, color change (from brown to black), and tubular growth were obtained at an appropriate distance from the burner. Later, Yuan et al. [27] synthesized CNTs using methane-air, ethylene-air, and $\mathrm{N}_{2}$-diluted ethylene-air [49] diffusion flame; the sample was collected on Ni-Cr wires and preoxidized Co-coated steel grids, which acted as a catalyst. SEM studies showed that the ending part of the nanotubes near the substrate was connected to the catalytic particle. This supported the base growth model of CNTs and, unlike the CVD process, the formation of the catalytic particle and CNT took place in the same process, thereby reducing costs [27].

According to Saito et al. [48] methane pyrolyzes, and the surface oxidation of $\mathrm{Ni}-\mathrm{Cr}-\mathrm{Fe}$ wire leads to the formation of catalyst-particle nickel and iron oxides; then, the pyrolyzed methane adsorbs on these catalyst particles, and the carbon precursors are produced. After diffusion and precipitation through the catalyst-particle nucleation, growth of CNT takes place [49]. Unlike methane, Ni-Cr supports the growth of amorphous carbon in ethane; this proves that the formation mechanism depends on the type of fuel used.

As the sampling time increases, the deposition of carbon onto nanotubes and the production rate increase. In addition, dilution with inert gas affects the morphology of CNTs by controlling 
soot formation [50]. Oxygen plays a vital role in the formation of metal oxides to catalyze the tube formation; however, the excess oxygen may damage CNTs by oxidizing them. Compared to non-coated steel grids, well-aligned and well-graphitized nanotubes can be obtained by using Co-coated steel grids.

The data reported in these aforementioned studies suggest that the supporting substrate controls the morphology and the growth rate of nanostructures due to electronic interactions. In 2000, Vander Wal et al. [51,52] synthesized single-walled carbon nanotubes (SWCNT) via diffusion flame using hydrocarbons diluted with inert gas; metallocene catalyst was used as a precursor. They reported that the formation of the catalyst particles and their entrainment into the high-temperature hydrocarbon environment played a central role in the formation of CNTs. The detailed investigation of the molecular path towards soot formation showed that acetylene was essentially required for the formation of the first aromatic ring, i.e., benzene ring, which leads to the polyaromatic hydrocarbon (PAH) growth.

In 2002, Merchan-Merchan et al. [53] used oxygen-enriched $(>50 \%)$ counter-flow diffusion flame without catalyst to fabricate CNTs; they found that the formed soots were significantly different from normal soots. A counter-flow burner was used to supply the fuel (top nozzle) and oxidizer (bottom nozzle). They observed that the quantity of nanotubes was low and detected only with oxygen enrichment larger than $50 \%$; moreover, the oxidizer side of the reaction zone of flame showed an increased amount of radicals, which in turn further increased the CNT yield. Notably, this was a cost-effective synthesis method because no catalysts were used. In a more recent study, they used the same counter-flow setup along with a Ni-based catalytic support positioned on the fuel side [54]; the observations were carried out at various radial regions of the flame and different heights. The transmission electron microscope (TEM) analysis revealed that the flame location strongly affected the presence of carbon structures. In addition, different morphologies of nanotubes and nanofibers were detected, suggesting that different carbon structures can be selectively formed even without varying the catalyst properties.

Merchan-Merchan et al. [55,56] also produced highlyaligned and uniform CNTs by using an electric field connected to a Ni catalyst and employing the oxy-rich counter-flow diffusion method. They showed that the morphology and synthesis rate of the nanostructures could be controlled by applying an electric field. Thus, the use of a counter-flow configuration may offer an improved sampling and provide better understanding.

In the same year, $\mathrm{Hu}$ et al. [57] used a silicon substrate with a porous-alumina template to produce vertically aligned multiwalled carbon nanotubes (MWCNTs); they found that the diameter and height of the obtained CNT were the same as those of the template. Additionally, they concluded that, along with the template, Co particles, which are deposited at the bottom of the template pores, were responsible for the well-graphitized CNT growth.

In 2009, Yang et al. [58] suggested a very simple and costeffective method to synthesize a large number of well-aligned CNTs for electronic applications; this was based on a photoresist-assisted catalyst annealing process with no diffusion barrier layer, which was responsible for the formation of the proper catalyst, leading to thinner, longer, and denser CNTs.

According to the aforementioned studies, it can be inferred that soot formation takes place over a temperature range of 1300 $1600 \mathrm{~K}$. In normal diffusion methods, soot formation occurs at the inner flame region, where the temperature is around $1600 \mathrm{~K}$, and the formation of CNTs takes place in the sooting zone of the diffusion flame. Therefore, the inverse-diffusion method, where the oxidizer is in the center and fuel is outside, was used for CNT production [59-62]. Lee et al. [59] synthesized MWCNTs on a stainless steel substrate coated with a nickel nitrate and observed that the effective zone for CNT production was located at 5-7 $\mathrm{mm}$ from the center.

Nanotubes and nanofibers form in the range of $800^{\circ} \mathrm{C}-1300^{\circ} \mathrm{C}$. Nanofibers are dominant in the range of $800^{\circ} \mathrm{C}-1000^{\circ} \mathrm{C}$, while the $1000^{\circ} \mathrm{C}-1300^{\circ} \mathrm{C}$ range is suitable for multi-walled nanotube synthesis. Xu et al. [60] showed that the temperature affects the structure and morphology of both CNTs and CNFs. In particular, CVD and counter-flow diffusion flames have a common temperature range of 1023-1073 K for CNT synthesis. In addition, the alloy composition (e.g., $\mathrm{Fe}, \mathrm{Ni} / \mathrm{Cu}, \mathrm{Ni} / \mathrm{Cr} / \mathrm{Fe}$ ), sampling positions within the flame structure, and voltage bias applied to the probe substrate also affect the synthesis [60] (Fig. 2). More recently, Unrau et al. [63] reported an excellent approach to fabricate SWCNTs using the inversion-diffusion flame with a high stoichiometric mixture fraction $\left(\mathrm{Z}_{\mathrm{st}}\right)$. A differential mobility analyzer (DMA) was used as an online diagnostic tool for determining nanotube size, number density, and purity [63]. According to this study, a high $Z_{\mathrm{st}}$ value leads to an increase in the formation of CNTs with less soot impurities, while the inverse arrangement is responsible for the transfer of CNTs into the fuel-rich zone after their formation.

The effects of fuel type on the formation mechanism were studied by Camacho and Choudhuri [64]. They reported that thin MWCNTs as well as nanorods and nanofibers can be produced by using methane, while only nanotubes were obtained when using propane. In addition, acetylene-fuel flames produced helically coiled and twisted nanotubes.

As stated above, the growth rate of CNTs or CNFs depends on the height of the burner [65], i.e., as the height above the burner increases, the growth rate decreases due to the decreasing temperature at higher locations, which suppresses the catalyst deactivation. In addition, as the height increases, the $\mathrm{CO}$ concentration decreases; this is the main factor responsible for the carbon precipitation. Manciu et al. [66] introduced a hydrogendoped fuel for the synthesis of nanotubes, which opened the way for coal utilization and bi-product synergism of coal-fired plants. They reported that the $\mathrm{H}_{2}$ concentration for the optimal yield of CNTs is around 5\%; at concentrations larger than $10 \%$, the formation of amorphous carbon and soot particles is more favorable compared to CNT formation. According to a previous study, the species that exist in the synthesis zone (e.g., $\mathrm{H}_{2}, \mathrm{CO}_{2}$, and $\mathrm{H}_{2} \mathrm{O}$ ) may promote the synthesis by activating the catalyst [67].

According to Hou et al. [68], a rotating counter-flow diffusion flame affects CNT fabrication. A diffusion flame with a high angular velocity (i.e., low strain rate) produces more carbon sources due to the longer dwelling time compared to a flame with high strain rate and low angular velocity. In addition, they observed that the nickel-nitrate coated nickel substrate can provide better 


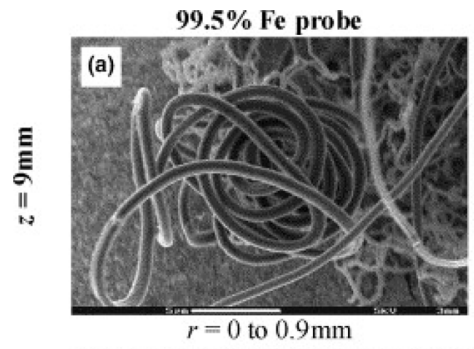

$\mathbf{4 5} \% \mathrm{Ni} / \mathbf{5 5} \%$ Cu probe

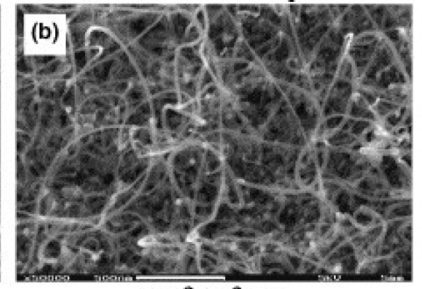
$r=2$ to $3 \mathrm{~mm}$

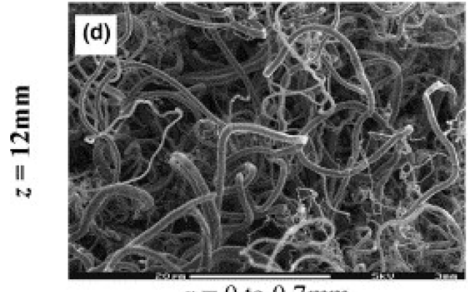

$r=0$ to $0.7 \mathrm{~mm}$

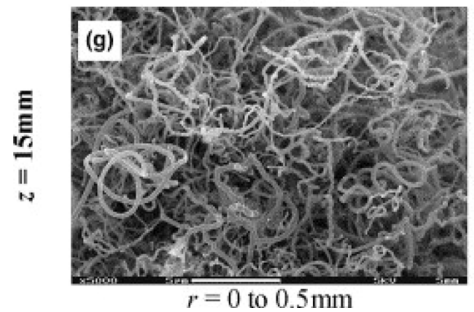

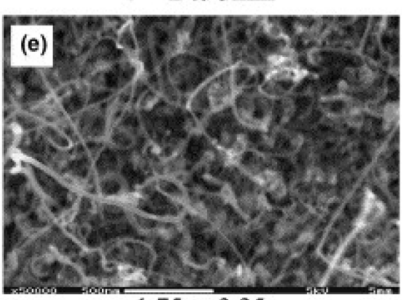

$r=1.75$ to $3.25 \mathrm{~mm}$

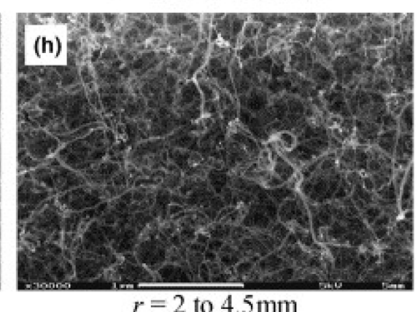

$60 \% \mathrm{Ni} / 16 \% \mathrm{Cr} / 24 \% \mathrm{Fe}$ probe
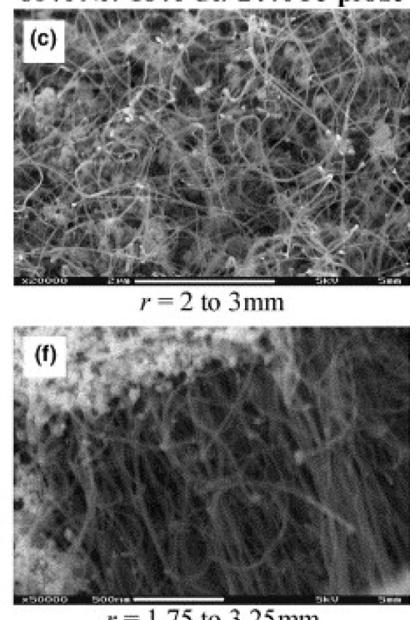

$r=1.75$ to $3.25 \mathrm{~mm}$

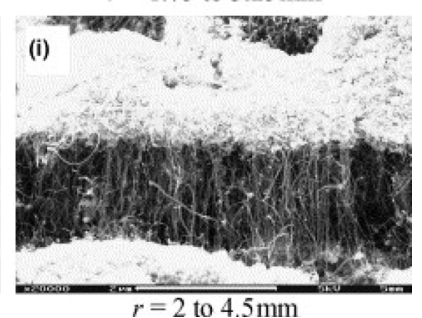

Fig. 2. Field-emission scanning electron microscope images of variation in carbon nanotube morphology corresponding to catalytic probe composition (column) and flame sampling height (row). Reprinted with permission from [60].

results compared to those of the uncoated nickel substrates.

Chung and Lin [69] studied the collective effects of acoustic excitation and $\mathrm{N}_{2}$ dilution on the synthesis of nanostructures. They found a uniform radial expansion of heat and adequate distribution carbon precursors in the flame due to acoustic excitation, which leads to an increased synthesis area.

Based on these properties, flame synthesis offers several advantages, as reported by Dhand et al. [70]: 1) the process is easy to scale-up for the bulk synthesis of carbon and several other nanomaterials; 2) the process offers a novel route for insitu catalyst generation; 3 ) once started, the synthesis becomes a continuous process; 4) it is easier to control the particle size during the synthesis reaction; 5) the supply gas (hydrocarbon/ precursor/fuel) serves a dual purpose; 6) the process is highly energy efficient. In their work, Dhand et al. [70] synthesized carbon nanorods with a large diameter using a methane-acetylene-oxygen diffusion flame in the absence of a catalyst. Their results suggest that the growth and crystallinity of the nanorods only depend on the flame temperature, and on the feed stock and flow rate of the fuel/oxygen, respectively. Similarly, Rao et al. [71] synthesized carbon nanorods in the presence of lithium acetate as a precursor, obtaining a good growth of the nanorods with a high degree of crystallinity due to a higher residence time as well as a good concentration of the precursor used. Rao et al. [71] also observed a decrease in the nanorod diameter due to the use of a catalyst precursor. In addition, the type of hydrocarbon feed used also contributed to the synthesis of good quality nanotubes/rods. In another study, Dhand et al. [12] used higher alkanes as the feed stock in the absence of catalyst. They reported that the use of the higher alkanes in higher flow rates favored the synthesis of nanorods/tubes over that of carbon nano-onions. Factors such as flow rate, oxidant-to-fuel ratio, and temperature were responsible for the formation of different carbon structures within the same flame environment.

\section{Premixed Flame Synthesis}

In a premixed flame, the fuel and oxidizer are mixed completely before ignition. Premixed flame synthesis methods have certain advantages over the diffusion flame method, including the availability of a broad range of fuels, continuous and multistaged processing, scalability of stoichiometry of reagent gases, flame temperature (can be reduced by using chimneys), reactive gas profile, and equivalent ratio [72].

A number of studies have been published on CNT formation through premixed flame synthesis. Initially, Howard et al. [73] reported the synthesis of carbon nanostructures derived from soots formed by the combustion of premixed flames of acetylene or benzene with oxygen and argon in low pressure ranges. In another experiment, they observed nanotubes and other nanostructures with different shapes and sizes (ranging between 2 and 30 $\mathrm{nm}$ with a hollow core and diameter of 1-10 nm) and containing 5-20 shells in soot produced by premixing of a diverse range of fuels (e.g., acetylene, benzene, and ethylene) premixed with oxygen and inert diluent gas [74]. The HRTEM analysis of the products showed that the CNT caps had different shapes; this was suggested to be caused by the longer residence time, which leads to more well-ordered graphitic and fullerenic shells in the wall and the caps. 

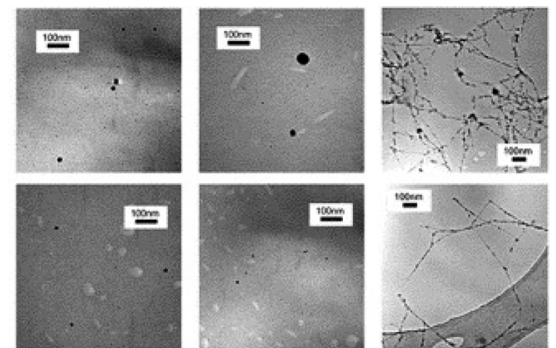

$\phi \quad 1.4$

1.5
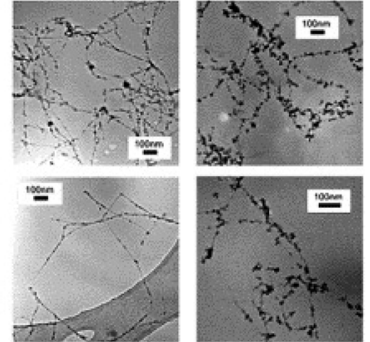

1.6

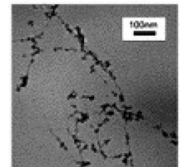

1.7
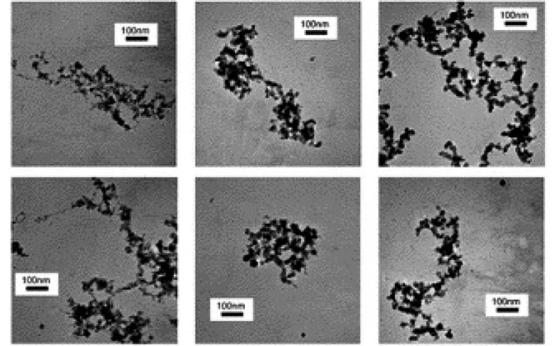

1.9
2.0

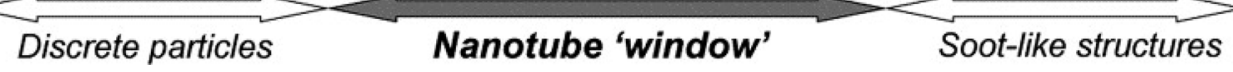

Fig. 3. Morphology variation with equivalence ratio $(\varphi)$ for samples at $70 \mathrm{~mm} \mathrm{HAB}$. Reprinted with permission from [85].

Such highly spherical fullerenic structures were formed due to the less energetic conditions of the hydrocarbon flames. Additionally, the yield of these structures is significantly lower $(\sim 10 \%)$ than those obtained with the arc-discharge method ( $\sim 0 \%-75 \%)$; similarly, the observed aspect ratio of flame-generated CNTs is lower than that of the arc-discharge generated CNTs. This confirms that the flame synthesis is a simpler/better approach for the production of CNTs.

Duan and McKinnon [75] also synthesized CNTs by premixing benzene and air in a low pressure range, finding that the generated CNTs were MWCNTs with open and closed ends, resulting from the complex environment of the flames, i.e., $\mathrm{O}_{2}$ and $\mathrm{CO}_{2}$ in the flame reacted with the carbon on the cap, opening it. A new type of nanocluster with non-hollow cores, consisting of a series of concentric tubes, was also obtained; these were considered to be hydrocarbon crystals. It was proved that the formation of fullerene or graphitic onions is more favorable than that of nanotubes [76]. However, unlike the arc-discharge method, where high pressure supports CNT growth and low gas pressure supports fullerene synthesis, both fullerene and CNTs can be produced in flame synthesis in large quantity under the same conditions.

To satisfy the massive demand for SWCNTs, a cost-effective and large-scale synthesis method was reported based on the sooting flames of premixed various hydrocarbon fuels (acetylene, ethylene, benzene) and oxygen by adding metallocene. This cannot be achieved with the arc-discharge or laser-ablation methods [77]. It was found that acetylene and ethylene fuels contained SWCNTs with few MWCNTs, while in the presence of benzene, only MWCNTs with many defects, sporadic metal filling, and lengths of more than $10 \mu \mathrm{m}$ were observed. The reason behind this is the rapid breaking of most of the benzene rings into acetylenic units during combustion. As mentioned earlier, soot formation occurs through PAH intermediates, which initially form a single aromatic ring i.e., benzene ring. Unlike acetylene and ethylene, benzene already contains a ring; therefore soot formation occurs earlier in benzene flames. Thus, soot formation starts when the metal particles have not sufficiently grown to catalyze the formation of SWCNTs. This flame technique favors the industrial-scale synthesis of SWCNTs over conventional methods.

Although several studies had earlier confirmed that flame synthesis was a cost-effective, large-scale continuous and scalable method for the production of high-purity CNTs, a systematic investigation of the parameters that affect CNT production was still to be done. Subsequently, Vander Wal et al. [52,78-84] conducted some detailed studies of CNTs synthesis in premixed hydrocarbon flames. In their studies, a McKenna burner was used with a stainless steel chimney at the top of the central fuel tube to stabilize the pyrolysis steam and collect the yield. Various hydrocarbon fuels (e.g., methane, ethane, propane, ethylene, and acetylene) with different metallic additives (e.g., cobaltocene, nickelocene, cobalt acetylacetonate, and ferrocene) were used by varying the flame equivalence ratios. In their setup, metallocene vapors were introduced within the inert gas (which was the main part of the pyrolysis flame), while the fuel-rich premixed flame was located in the outer part of the burner. The results of the study suggested that only the central flame that contained the cyclopentadienyl moieties of metallocene was not the main carbon source; instead, it synergistically supported the CNT growth with the hydrocarbon fuels [78].

As catalyst particles in aerosol form are necessary for flame synthesis, Vander Wal and co-workers investigated different approaches to introduce them into the flames. In one report, a nebulization technique was used to create an aerosol of liquid droplets containing the catalyst (a metal nitrate or ferrofluid) in soluble form, after drying these particles introduced within inert gas or $\mathrm{CO}$ [79]. It was observed that the particle size obtained by this method was controlled and uniform, which is favorable for producing uniform SWCNTs. Similarly, SWCNTs were synthesized within the pyrolysis flame using sublimed ferrocene as a metal catalyst precursor [80]; the sublimation temperature was controlled via the mass introduction rate by adjusting the height of the sample holder within the burner central fuel tube.

In another study, a filter paper was loaded with an iron nitrate solution and burned to create an aerosol of the catalyst particles [84]; this was then introduced into the fuel-rich region. In other studies, substrate-supported catalyst methods were used $[72,81,84]$. The substrate can also interact physically or chemically with the catalyst particles and may control their catalytic activity.

More recently, Height et al. [85] carried out a detailed investigation of the nanotube formation zone, growth time scale, transition conditions, and tube structure under different operat- 
Table 1. Various CNTs synthesized from different burner configurations Reprinted with permission from [26].

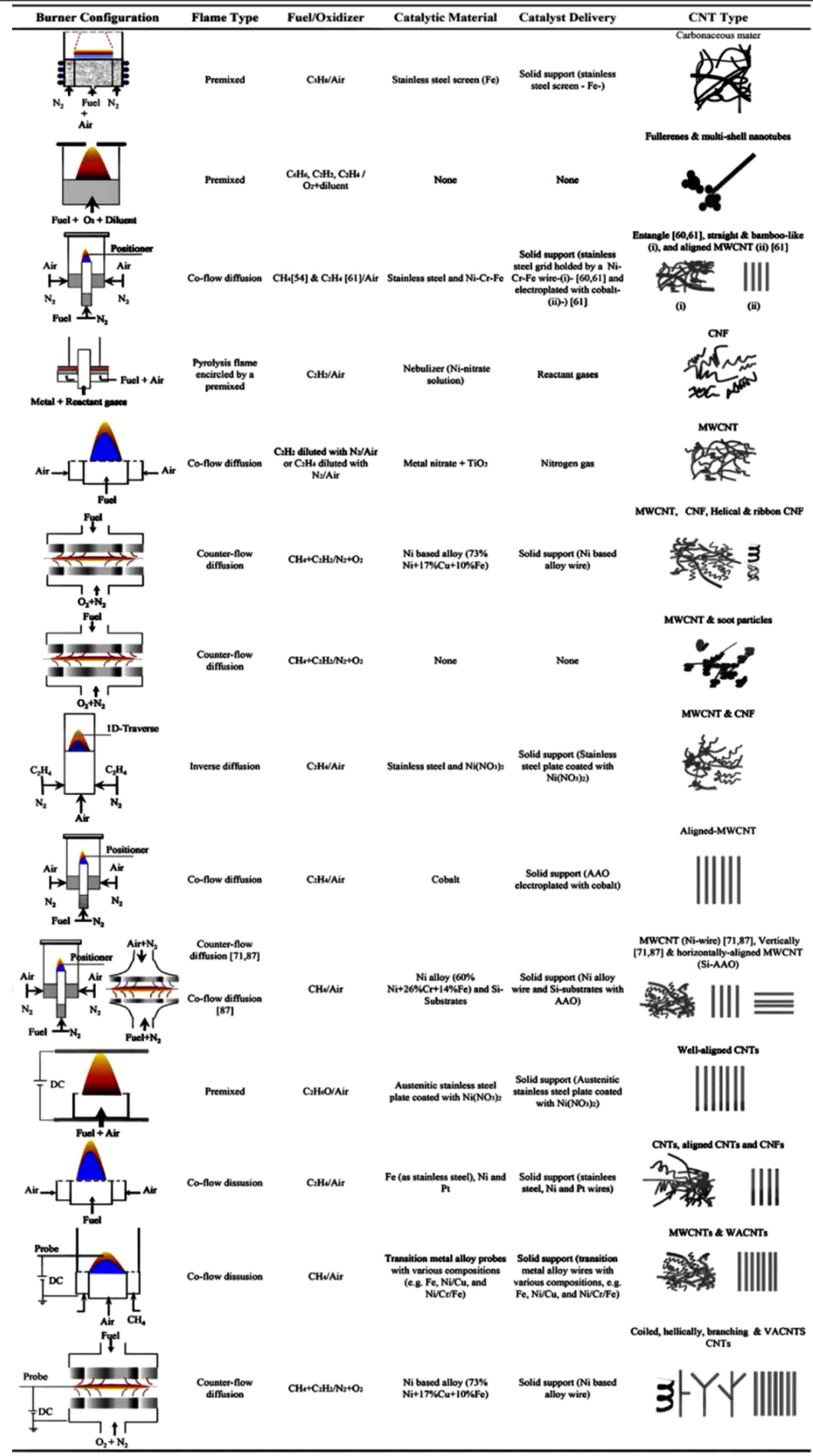


Table 2. Different burner configurations and produced SWCNTs Reprinted with permission from [26].

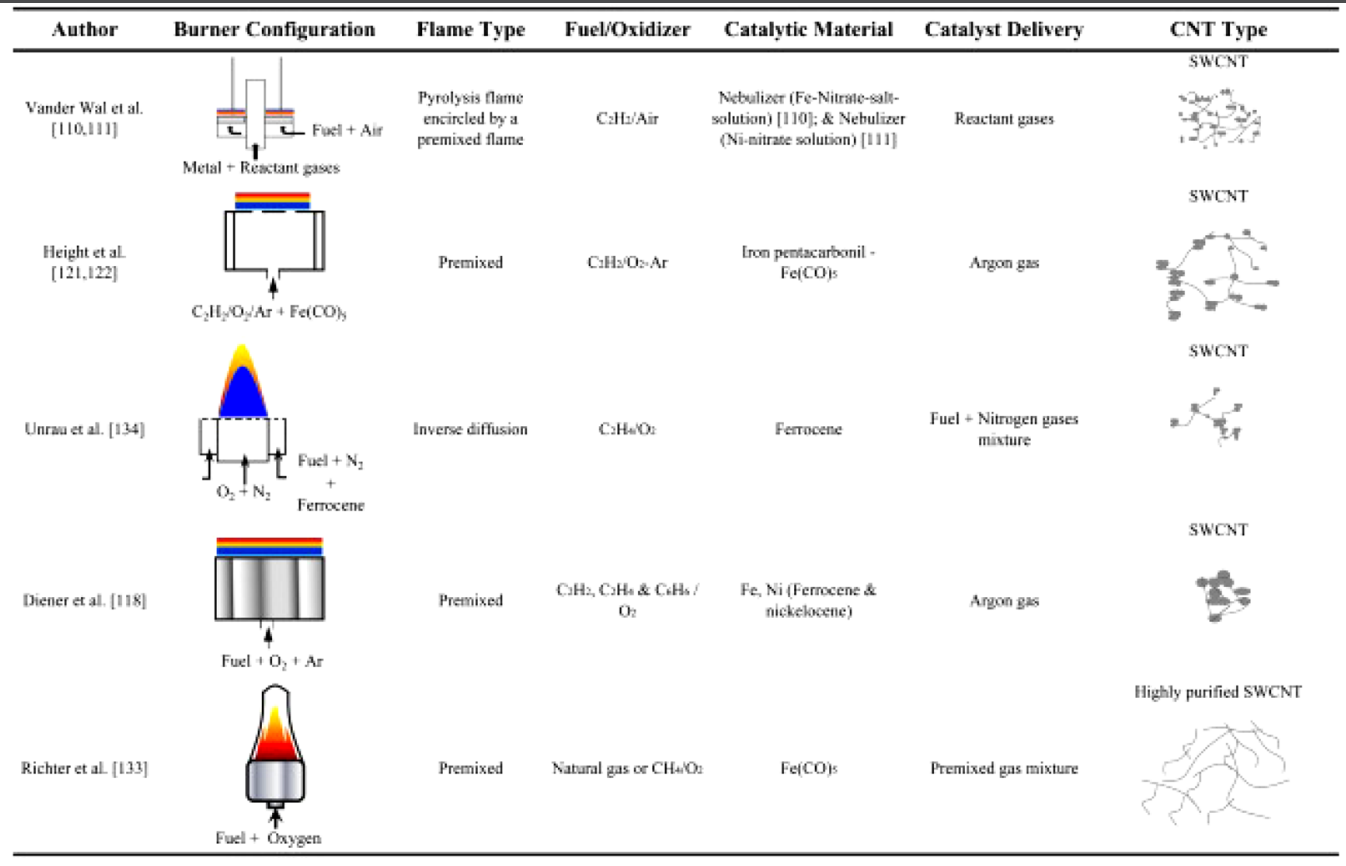

ing conditions. SWCNTs were produced in a post-flame region of a premixed flame of acetylene/oxygen $/ 15 \mathrm{~mol} \% \mathrm{Ar}$ at $6.7 \mathrm{kPa}$ in the presence of $\mathrm{Fe}(\mathrm{CO})_{5}$ as a catalyst. The yield was analyzed at various heights above the burner (HAB) by using thermophoretic sampling and TEM. It was found that catalytic particles formation and growth occurred in the immediate post-flame region (10-40 mm HAB). The inception of nanotubes started from $30 \mathrm{~mm}$ HAB; between 40 and $70 \mathrm{~mm} \mathrm{HAB}$, SWCNTs with a diameter of $0.9-1.5 \mathrm{~nm}$ were observed in clusters. The formation of this "window" was valid only between 1.5 and 1.9 equivalent ratios [85] (Fig. 3).

Notably, several computational and experimental studies have been performed to achieve a deeper understanding of the controlling parameters and growth mechanisms for premixed flame synthesis $[36,56,65,86-90]$. On the basis of the above discussion, it can be concluded that the premixed flame synthesis of CNTs has several advantages over diffusion flame synthesis. In particular, the flame environment plays a vital role; its chemical and thermal profiles can be easily altered by varying the fuel-air equivalence ratio or by introducing/ eliminating the gases that evade the varying gas-phase composition generated by the hydrocarbon pyrolysis processes. Moreover, this method is scalable, and a uniform temperature can be attained across the burner surface; this helps avoid steep spatial gradients in the temperature or species. Unlike the diffusion technique, the premixed flame synthesis is not complex and flame composition can be understood through thermodynamic equilibrium computational algorithms. This method favors rapid combustion and supports manageable flame for laboratory investigations. These benefits provide the basic understanding and potential scalability of the CNT synthesis. However, safety is still a major issue, as there is a constant probability of detonation.

It should thus be mentioned that both techniques present ad- vantages and drawbacks; for instance, the diffusion method is less scalable, but the safety of the premixed flame method is of concern. Therefore, it is hard to establish which of the two techniques is the best. Nevertheless, both the methods enable the fast and large-scale production of CNTs and can be altered by controlling various critical parameters.

In particular, the height of the flame controls the morphology and the structures of the carbon material; the equivalence ratio plays an important role in the production yield, and large-scale production can be achieved by optimizing this parameter. Typically, investigations related to the equivalence ratio are performed on premixed flame as it possesses equal equivalence ratio throughout the flame. It was found that the diameter, length, and yield decrease as the equivalence ratio increases. The residence time is directly proportional to the growth rate. The temperature also has a significant role in the CNT growth. In particular, temperature and the availability of carbon precursors change with location in the flame; consequently, the growth mechanism changes. Acetylene and $\mathrm{CO}$ are the leading precursors which support the growth of CNTs. Various transition metals are used to catalyze the CNT growth; the mechanism varies depending on the catalyst properties, such as particle size, melting points, etc.

Suffice to say, numerous flame synthesis configurations can be used to synthesize CNTs in a cost-efficient and energy-efficient way. Moreover, by altering the operation parameters and conditions, various other carbon structures can also be obtained in addition to CNTs, with different morphologies. Furthermore, this simple method may meet the vast demand for large-scale production of SWCNTs for industrial applications such as energy storage, hydrogen storage, and composites. These various set-ups, configurations, obtained structures and other information are accumulated in Tables 1 and 2 [26]. 


\section{Conclusion}

This review outlines the economical approaches to large-scale production of CNTs and other carbon structures. Flame synthesis is acknowledged as a low-cost method, as it does not need any complex process or controlled temperature/pressure for its functionality. Several other nanostructures can also be obtained by altering various operating parameters, such as hydrocarbon precursors, burner configurations, additives, catalysts, temperature, distance, and height from the burner, respectively. A much deeper understanding of the factors that influence the synthesis is required for the development of a large-scale production of these flame synthesized nanomaterials, which in future will be used for various commercial applications.

\section{Acknowledgements}

This work was financially supported by the National R\&D project of "Development of Energy Utilization Technology of Deep Sea Water Resource" supported by the Ministry of Oceans and Fisheries of the Republic of Korea.

\section{References}

[1] Karthik PS, Himaja AL, Singh SP. Carbon-allotropes: synthesis methods, applications and future perspectives. Carbon Lett, 15, 219 (2014). http://dx.doi.org/10.5714/CL.2014.15.4.219.

[2] Watanabe K, Araidai M, Tada K. Field emission and electronic structures of carbon allotropes. Thin Solid Films, 464-465, 354 (2004). http://dx.doi.org/10.1016/j.tsf.2004.06.048.

[3] Lee JH, Marroquin J, Rhee KY, Park SJ, Hui D. Cryomilling application of graphene to improve material properties of graphene/ chitosan nanocomposites. Composites B, 45, 682 (2013). http:// dx.doi.org/10.1016/j.compositesb.2012.05.011.

[4] Yadav M, Rhee KY, Jung IH, Park SJ. Eco-friendly synthesis, characterization and properties of a sodium carboxymethyl cellulose graphene oxide nanocomposite film. Cellulose, 20, 687 (2013). http://dx.doi.org/10.1007/s10570-012-9855-5

[5] Bae KM, Park SJ. A study on elemental mercury adsorption behaviors of nanoporous carbons with carbon dioxide activation. Carbon Lett, 15, 295 (2014). http://dx.doi.org/10.5714/CL.2014.15.4.295.

[6] Bae KM, Kim BJ, Park SJ. Overlook of carbonaceous adsorbents and processing methods for elemental mercury removal. Carbon Lett, 15, 238 (2014). http://dx.doi.org/10.5714/CL.2014.15.4.238

[7] Azeez AA, Rhee KY, Park SJ, Kim HJ, Jung DH. Application of cryomilling to enhance material properties of carbon nanotube reinforced chitosan nanocomposites. Composites B, 50, 127 (2013). http://dx.doi.org/10.1016/j.compositesb.2013.01.010.

[8] Sun F, Shi C, Rhee KY, Zhao N. In-situ synthesis of CNTs in Mg powder at low temperature for fabricating reinforced $\mathrm{Mg}$ composites. J Alloys Compd, 551, 496 (2013). http://dx.doi.org/10.1016/j. jallcom.2012.11.053

[9] Zhao Z, Gou J, Bietto S, Ibeh C, Hui D. Fire retardency of clay/carbon nanofiber hybrid sheet in fiber reinforced polymer composites. Compos Sci Technol, 69, 2081 (2009). http://dx.doi.org/10.1016/j. compscitech.2008.11.004.
[10] Kim MT, Rhee KY, Lee JH, Hui D, Lau AKT. Property enhancement of a carbon fiber/epoxy composite by using carbon nanotubes. Composites B, 42, 1257 (2011). http://dx.doi.org/10.1016/j. compositesb.2011.02.005.

[11] Roessler DM, Wang DSY, Kerker M. Optical absorption by randomly oriented carbon spheroids. Appl Opt, 22, 3648 (1983). http://dx.doi.org/10.1364/AO.22.003648.

[12] Dhand V, Prasad JS, Rao MV, Bharadwaj S, Anjaneyulu Y, Jain PK. Flame synthesis of carbon nano onions using liquefied petroleum gas without catalyst. Mater Sci Eng C, 33, 758 (2013). http:// dx.doi.org/10.1016/j.msec.2012.10.029.

[13] Prato M. [60]Fullerene chemistry for materials science applications. J Mater Chem, 7, 1097 (1997). http://dx.doi.org/10.1039/ A700080D.

[14] Schueller OJA, Brittain ST, Whitesides GM. Fabrication of glassy carbon microstructures by soft lithography. Sens Actuators A, 72 125 (1999). http://dx.doi.org/10.1016/S0924-4247(98)00218-0.

[15] Mittal G, Dhand V, Rhee KY, Park SJ, Le WR. A review on carbon nanotubes and graphene as fillers in reinforced polymer nanocomposites. J Ind Eng Chem, 21, 11 (2015). http://dx.doi.org/10.1016/j. jiec.2014.03.022.

[16] Ibrahim KS. Carbon nanotubes-properties and applications: a review. Carbon Lett, 14, 131 (2013). http://dx.doi.org/10.5714/ CL.2013.14.3.131

[17] Kim YA, Yang KS, Muramatsu H, Hayashi T, Endo M, Terrones M, Dresselhaus MS. Double-walled carbon nanotubes: synthesis, structural characterization, and application. Carbon Lett, 15, 77 (2014). http://dx.doi.org/10.5714/CL.2014.15.2.077.

[18] Prasek J, Drbohlavova J, Chomoucka J, Hubalek J, Jasek O, Adam V, Kizek R. Methods for carbon nanotubes synthesis: review. J Mater Chem, 21, 15872 (2011). http://dx.doi.org/10.1039/C1JM12254A

[19] Iijima S. Helical microtubules of graphitic carbon. Nature, 354, 56 (1991). http://dx.doi.org/10.1038/354056a0.

[20] Park YS, Moon HS, Huh M, Kim BJ, Kuk YS, Kang SJ, Lee SH, An KH. Synthesis of aligned and length-controlled carbon nanotubes by chemical vapor deposition. Carbon Lett, 14, 99 (2013). http://dx.doi.org/10.5714/CL.2013.14.2.099.

[21] Kumar M, Ando Y. Chemical vapor deposition of carbon nanotubes: a review on growth mechanism and mass production. J Nanosci Nanotechnol, 10, 3739 (2010). http://dx.doi.org/10.1166/ jnn.2010.2939.

[22] Dupuis AC. The catalyst in the CCVD of carbon nanotubes: a review. Prog Mater Sci, 50, 929 (2005). http://dx.doi.org/10.1016/j. pmatsci.2005.04.003

[23] Yudasaka M, Yamada R, Sensui N, Wilkins T, Ichihashi T, Iijima $\mathrm{S}$. Mechanism of the effect of $\mathrm{NiCo}, \mathrm{Ni}$ and Co catalysts on the yield of single-wall carbon nanotubes formed by pulsed Nd:YAG laser ablation. J Phys Chem B, 103, 6224 (1999). http://dx.doi. org/10.1021/jp9908451.

[24] Sharon M, Rusop M, Soga T, Afre RA. Laser ablated carbon thin film from carbon nanotubes and their property studies. Carbon Lett, 9, 17 (2008)

[25] Charcosset C, Bernard S, Fiaty K, Bechelany M, Cornu D. Membrane techniques for the preparation of nanomaterials: nanotubes, nanowires and nanoparticles: a review. Dyn Biochem Process Biotechnol Mol Biol, 1, 15 (2007).

[26] Merchan-Merchan W, Saveliev AV, Kennedy L, Jimenez WC Combustion synthesis of carbon nanotubes and related nanostruc- 
tures. Prog Energy Combust Sci, 36, 696 (2010). http://dx.doi org/10.1016/j.pecs.2010.02.005.

[27] Yuan L, Saito K, Pan C, Williams FA, Gordon AS. Nanotubes from methane flames. Chem Phys Lett, 340, 237 (2001). http://dx.doi. org/10.1016/S0009-2614(01)00435-3.

[28] Woo SK, Hong YT, Kwon OC. Flame synthesis of carbon nanotubes using a double-faced wall stagnation flow burner. Carbon, 47, 912 (2009). http://dx.doi.org/10.1016/j.carbon.2008.11.052.

[29] Singer JM, Grumer J. Carbon formation in very rich hydrocarbonair flames: I. Studies of chemical content, temperature, ionization and particulate matter. Symp Int Combust, 7, 559 (1958). http:// dx.doi.org/10.1016/S0082-0784(58)80092-2.

[30] Njuguna J, Pielichowsky K. Polymer nanocomposites for aerospace application: fabrication. Adv Eng Mater, 6, 193 (2004). http://dx.doi.org/10.1002/adem.200305111.

[31] Nakazawa S, Yokomori T, Mizomoto M. Flame synthesis of carbon nanotubes in a wall stagnation flow. Chem Phys Lett, 403, 158 (2005). http://dx.doi.org/10.1016/j.cplett.2004.12.091.

[32] Okuno H, Issi JP, Charlier JC. Catalyst assisted synthesis of carbon nanotubes using the oxy-acetylene combustion flame method. Carbon, 43, 864 (2005). http://dx.doi.org/10.1016/j.carbon.2004.10.041.

[33] Cao F, Yang H, Fu Q, Pan CX. Influence of fuels and substrates on flame synthesis of one-dimensional carbon nanomaterials. New Carbon Mater, 20, 261 (2005).

[34] Arana CP, Puri IK, Sen S. Catalyst influence on the flame synthesis of aligned carbon nanotubes and nanofibers. Proc Combust Inst, 30, 2553 (2005). http://dx.doi.org/10.1016/j.proci.2004.08.077.

[35] Roper FG. The prediction of laminar jet diffusion flame sizes: Part I. Theoretical model. Combust Flame, 29, 219 (1977). http:// dx.doi.org/10.1016/0010-2180(77)90112-2.

[36] Woo SK, Hong YT, Kwon OC. Flame-synthesis limits and selfcatalytic behavior of carbon nanotubes using a double-faced wall stagnation flow burner. Combust Flame, 156, 1983 (2009). http:// dx.doi.org/10.1016/j.combustflame.2009.07.003.

[37] Rao CNR, Satishkumar BC, Govindaraj A, Nath M. Nanotubes. ChemPhysChem, 2, 78 (2001). http://dx.doi.org/10.1002/14397641(20010216)2:2<78::AID-CPHC78>3.0.CO;2-7.

[38] Zhang XF, Yang XY, Qi WW, Yu SY. Experimental research on synthesis of carbon nanotubes. J Eng Thermophys, 27, 357 (2006).

[39] Dhand V, Rao MV, Prasad JS, Mittal G, Rhee KY, Kim HJ, Jung DH. Carbon nanospheres synthesized via solution combustion method: their application as an anode material and catalyst for hydrogen production. Carbon Lett, 15, 198 (2014). http://dx.doi org/10.5714/CL.2014.15.3.198.

[40] Dhand V, Prasad JS, Rao MV, Kalluri S, Jain PK, Sreedhar B. Hydrogen adsorption in flame synthesized and lithium intercalated carbon nanofibers: a comparative study. J Nanosci Nanotechnol, 15, 742 (2015). http://dx.doi.org/10.1166/jnn.2015.9168.

[41] Dhand V, Prasad JS, Rhee KY, Anjaneyulu Y. Fabrication of high pressure hydrogen adsorption/desorption unit: adsorption study on flame synthesized carbon nanofibers. J Ind Eng Chem, 19, 944 (2013). http://dx.doi.org/10.1016/j.jiec.2012.11.013.

[42] Burghard M, Klauk H, Kern K. Carbon-based field-effect transistors for nanoelectronics. Adv Mater, 21, 2586 (2009). http://dx.doi. org/10.1002/adma.200803582.

[43] Lau KT, Wong TT, Leng J, Hui D, Rhee KY. Property enhancement of polymer-based composites at cryogenic environment by using tailored carbon nanotubes. Composites B, 54, 41 (2013). http:// dx.doi.org/10.1016/j.compositesb.2013.03.044.

[44] Lim JI, Rhee KY, Kim HJ, Jung DH. Effect of stacking sequence on the flexural and fracture properties of carbon/basalt/epoxy hybrid composites. Carbon Lett, 15, 125 (2014). http://dx.doi. org/10.5714/CL.2014.15.2.125.

[45] Kshirsagar DE, Puri V, Sharon M, Sharon M. Microwave absorption study of carbon nano materials synthesized from natural oils. Carbon Lett, 7, 245 (2006).

[46] Kim MS, Lim SM, Song MY, Cho HJ, Choi YH, Yu JS. Acid treatments of carbon nanotubes and their application as Pt-Ru/CNT anode catalysts for proton exchange membrane fuel cell. Carbon Lett, 11, 336 (2010). http://dx.doi.org/10.5714/CL.2010.11.4.336.

[47] Gore JP, Sane A. Flame synthesis of carbon nanotubes. In: Yellampalli S, ed. Carbon Nanotubes: Synthesis, Characterization, Applications, InTech, Chapter 7 (2011). http://dx.doi.org/10.5772/21012

[48] Saito K, Gordon AS, Williams FA, Stickle WF. A study of the early history of soot formation in various hydrocarbon diffusion flames. Combust Sci Technol, 80, 103 (1991). http://dx.doi. org/10.1080/00102209108951779.

[49] Yuan L, Li T, Saito K. Growth mechanism of carbon nanotubes in methane diffusion flames. Carbon, 41, 1889 (2003). http://dx.doi. org/10.1016/S0008-6223(03)00204-5.

[50] Yuan L, Saito K, Hu W, Chen Z. Ethylene flame synthesis of wellaligned multi-walled carbon nanotubes. Chem Phys Lett, 346, 23 (2001). http://dx.doi.org/10.1016/S0009-2614(01)00959-9.

[51] Vander Wal RL, Ticich TM, Curtis VE. Diffusion flame synthesis of single-walled carbon nanotubes. Chem Phys Lett, 323, 217 (2000). http://dx.doi.org/10.1016/S0009-2614(00)00522-4.

[52] Vander Wal RL, Berger GM, Hall LJ. Single-walled carbon nanotube synthesis via a multi-stage flame configuration. J Phys Chem B, 106, 3564 (2002). http://dx.doi.org/10.1021/jp012844q.

[53] Merchan-Merchan W, Saveliev A, Kennedy LA, Fridman A. Formation of carbon nanotubes in counter-flow, oxy-methane diffusion flames without catalysts. Chem Phys Lett, 354, 20 (2002). http://dx.doi.org/10.1016/S0009-2614(02)00027-1.

[54] Saveliev AV, Merchan-Merchan W, Kennedy LA. Metal catalyzed synthesis of carbon nanostructures in an opposed flow methane oxygen flame. Combust Flame, 135, 27 (2003). http://dx.doi. org/10.1016/S0010-2180(03)00142-1.

[55] Merchan-Merchan W, Saveliev AV, Kennedy LA. High-rate flame synthesis of vertically aligned carbon nanotubes using electric field control. Carbon, 42, 599 (2004). http://dx.doi.org/10.1016/j. carbon.2003.12.086.

[56] Merchan-Merchan W, Saveliev AV, Kennedy LA. Flame nanotube synthesis in moderate electric fields: from alignment and growth rate effects to structural variations and branching phenomena. Carbon, 44, 3308 (2006). http://dx.doi.org/10.1016/j.carbon.2006.06.025.

[57] Hu W, Yuan L, Chen Z, Gong D, Saito K. Fabrication and characterization of vertically aligned carbon nanotubes on silicon substrates using porous alumina nanotemplates. J Nanosci Nanotechnol, 2, 203 (2002). http://dx.doi.org/10.1166/jnn.2002.104.

[58] Yang X, Fang G, Liu N, Wang C, Zheng Q, Zhou H, Zhao D, Long $\mathrm{H}$, Liu Y, Zhao X. Synthesis and field emission properties of carbon nanotubes grown in ethanol flame based on a photoresist-assisted catalyst annealing process. Appl Surf Sci, 255, 7905 (2009). http:// dx.doi.org/10.1016/j.apsusc.2009.04.156.

[59] Lee GW, Jurng J, Hwang J. Synthesis of carbon nanotubes on a catalytic metal substrate by using an ethylene inverse diffusion 
flame. Carbon, 42, 682 (2004). http://dx.doi.org/10.1016/j.carbon.2003.12.081.

[60] Xu F, Liu X, Tse SD. Synthesis of carbon nanotubes on metal alloy substrates with voltage bias in methane inverse diffusion flames. Carbon, 44, 570 (2006). http://dx.doi.org/10.1016/j.carbon.2005.07.043.

[61] Li TX, Zhang HG, Wang FJ, Chen Z, Saito K. Synthesis of carbon nanotubes on Ni-alloy and Si-substrates using counterflow methane: air diffusion flames. Proc Combust Inst, 31, 1849 (2007). http://dx.doi.org/10.1016/j.proci.2006.07.194.

[62] Unrau CJ, Axelbaum RL, Biswas P, Fraundorf P. Synthesis of single-walled carbon nanotubes in oxy-fuel inverse diffusion flames with online diagnostics. Proc Combust Inst, 31, 1865 (2007). http://dx.doi.org/10.1016/j.proci.2006.08.009.

[63] Unrau CJ, Axelbaum RL, Lo CS. High-yield growth of carbon nanotubes on composite $\mathrm{Fe} / \mathrm{Si} / \mathrm{O}$ nanoparticle catalysts: a Car-Parrinello molecular dynamics and experimental study. J Phys Chem C, 114, 10430 (2010). http://dx.doi.org/10.1021/jp909255r.

[64] Camacho J, Choudhuri AR. Effects of fuel compositions on the structure and yield of flame synthesized carbon nanotubes. Fuller Nanotube Carbon Nanostruct, 15, 99 (2007). http://dx.doi. org/10.1080/15363830601177826.

[65] Naha S, Sen S, De AK, Puri IK. A detailed model for the flame synthesis of carbon nanotubes and nanofibers. Proc Combust Inst, 31, 1821 (2007). http://dx.doi.org/10.1016/j.proci.2006.07.224.

[66] Manciu FS, Camacho J, Choudhuri AR. Flame synthesis of multi-walled carbon nanotubes using $\mathrm{CH}_{4}-\mathrm{H}_{2}$ fuel blends. Fuller Nanotube Carbon Nanostruct, 16, 231 (2008). http://dx.doi. org/10.1080/15363830802171511.

[67] Li TX, Kuwana K, Saito K, Zhang H, Chen Z. Temperature and carbon source effects on methane: air flame synthesis of CNTs Proc Combust Inst, 32, 1855 (2009). http://dx.doi.org/10.1016/j. proci.2008.06.143

[68] Hou SS, Chung DH, Lin TH. Flame synthesis of carbon nanotubes in a rotating counterflow. J Nanosci Nanotechnol, 9, 4826 (2009). http://dx.doi.org/10.1166/jnn.2009.1277.

[69] Chung DH, Lin TH. Nitrogen dilution effect on flame synthesis of carbon nanostructures with acoustic modulation. J Phys Chem C, 115, 16287 (2011). http://dx.doi.org/10.1021/jp2023132.

[70] Dhand V, Prasad JS, Rao MV, Mahesh KN, Anupama L, Himabindu V, Yerramilli A, Raju VS, Sukumar AA. Design and development of flame reactor for carbon nanorods (CNRs) production. Indian J Eng Mater Sci, 14, 240 (2007).

[71] Rao MV, Dhand V, Prasad JS, Mahesh KN, Himabindu V, Yerramilli A, Sreedhar B. In situ lithium intercalation of carbon nanorods using flame synthesis. Compos Sci Technol, 70, 255 (2010). http://dx.doi.org/10.1016/j.compscitech.2009.10.016.

[72] Vander Wal RL, Hall LJ, Berger GM. Optimization of flame synthesis for carbon nanotubes using supported catalyst. J Phys Chem B, 106, 13122 (2002). http://dx.doi.org/10.1021/jp0206141.

[73] Howard JB, Chowdhury KD, Vander Sande JB. Carbon shells in flames. Nature, 370, 6491 (1994). http://dx.doi. org/10.1038/370603a0.

[74] Chowdhury KD, Howard JB, Vander Sande JB. Fullerenic nano- structures in flames. J Mater Res, 11, 341 (1996). http://dx.doi org/10.1557/JMR.1996.0040

[75] Duan HM, McKinnon JT. Nanoclusters produced in flames. J Phys Chem, 98, 12815 (1994). http://dx.doi.org/10.1021/j100100a001.

[76] Adams GB, Sankey OF, Page JB, O'Keeffe M, Drabold DA. Energetics of large fullerenes: balls, tubes, and capsules. Science, 256, 1792 (1992). http://dx.doi.org/10.1126/science.256.5065.1792.

[77] Diener MD, Nichelson N, Alford JM. Synthesis of single-walled carbon nanotubes in flames. J Phys Chem B, 104, 9615 (2000). http://dx.doi.org/10.1021/jp001233f.

[78] Vander Wal RL, Ticich TM, Curtis VE. Flame synthesis of metalcatalyzed single-wall carbon nanotubes. J Phys Chem A, 104, 7209 (2000). http://dx.doi.org/10.1021/jp994304n.

[79] Vander Wal RL, Ticich TM. Comparative flame and furnace synthesis of single-walled carbon nanotubes. Chem Phys Lett, 336, 24 (2001). http://dx.doi.org/10.1016/S0009-2614(01)00114-2.

[80] Vander Wal RL, Hall LJ. Ferrocene as a precursor reagent for metal-catalyzed carbon nanotubes: competing effects. Combust Flame, 130, 27 (2002). http://dx.doi.org/10.1016/S0010-2180(02)00358

[81] Vander Wal RL, Ticich TM. Flame and furnace synthesis of singlewalled and multi-walled carbon nanotubes and nanofibers. J Phys Chem B, 105, 10249 (2001). http://dx.doi.org/10.1021/jp012838u.

[82] Vander Wal RL, Ticich TM, Curtis VE. Substrate: support interactions in metal-catalyzed carbon nanofiber growth. Carbon, 39 2277 (2001). http://dx.doi.org/10.1016/S0008-6223(01)00047-1.

[83] Vander Wal RL, Hall LJ. Flame synthesis of Fe catalyzed singlewalled carbon nanotubes and $\mathrm{Ni}$ catalyzed nanofibers: growth mechanism and consequences. Chem Phys Lett, 349, 178 (2001). http://dx.doi.org/10.1016/S0009-2614(01)01198-8.

[84] Vander Wal RL, Hall LJ, Berger GM. The chemistry of premixed flame synthesis of carbon nanotubes using supported catalysts Proc Combust Inst, 29, 1079 (2002). http://dx.doi.org/10.1016 S1540-7489(02)80136-5.

[85] Height MJ, Howard JB, Tester JW, Vander Sande JB. Flame synthesis of single-walled carbon nanotubes. Carbon, 42, 2295 (2004) http://dx.doi.org/10.1016/j.carbon.2004.05.010.

[86] Gopinath P, Gore J. Chemical kinetic considerations for postflame synthesis of carbon nanotubes in premixed flames using a support catalyst. Combust Flame, 151, 542 (2007). http://dx.doi. org/10.1016/j.combustflame.2006.05.004.

[87] Height MJ, Howard JB, Tester JW, Vander Sande JB. Carbon nanotube formation and growth via particle-particle interaction. J Phys Chem B, 109, 12337 (2005). http://dx.doi.org/10.1021/jp046021n.

[88] Wen JZ, Thomson MJ, Lightstone MF, Rogak SN. Detailed kinetic modeling of carbonaceous nanoparticle inception and surface growth during the pyrolysis of $\mathrm{C}_{6} \mathrm{H}_{6}$ behind shock waves. Energy Fuels, 20, 547 (2006). http://dx.doi.org/10.1021/ef050081q

[89] Yu XL, Yang XY, Ye P, Wang J, Yu SY. Experimental study on multi-walled carbon nanotubes synthesized by acetylene-air premixed flame. J Eng Thermophys, 30, 165 (2009).

[90] Hall B, Zhuo C, Levendis YA, Richter H. Influence of the fuel structure on the flame synthesis of carbon nanomaterials. Carbon, 49, 3412 (2011). http://dx.doi.org/10.1016/j.carbon.2011.04.036. 